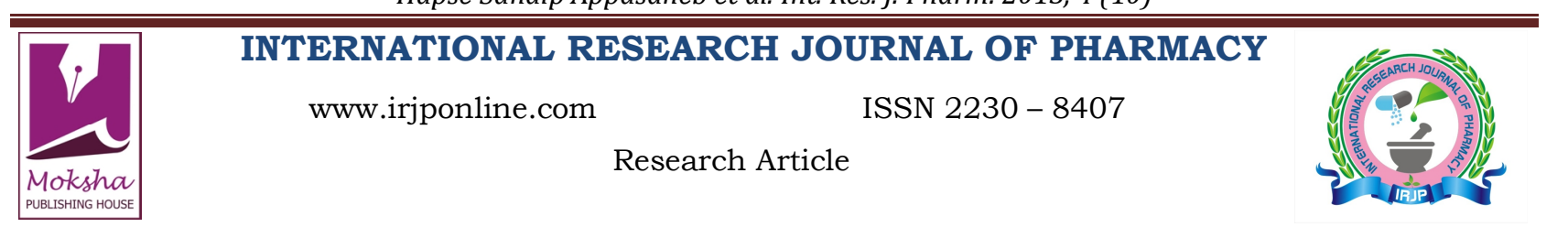

\title{
SIMULTANEOUS ESTIMATION AND VALIDATION OF PARACETAMOL, CHLORPHENIRAMINE MALEATE AND PHENYLEPHRINE HYDROCHLORIDE IN BULK AND TABLET DOSAGE FORM BY USING DIFFERENT SPECTROPHOTOMETRIC METHOD
}

Hapse Sandip Appasaheb*, Kapare Parmeshwar Subhash, Dhumal Virashri Atmaram, Damale Pallavi Shankar

PDVVPF'S College of Pharmacy, Post- MIDC, Vilad Ghat, Ahmednagar, (MS), India

*Corresponding Author Email: sandiphapse@gmail.com

Article Received on: 19/09/13 Revised on: 21/10/13 Approved for publication: 10/10/13

DOI: 10.7897/2230-8407.041010

IRJP is an official publication of Moksha Publishing House. Website: www.mokshaph.com

(C) All rights reserved.

\section{ABSTRACT}

A simple, precise, accurate and economic simultaneous UV spectrophotometric method has been developed for the estimation of Paracetamol, Chlorpheniramine Maleate and Phenylephrine Hydrochloride in combination in bulk mixture and tablet. The estimation was based upon measurement of absorbance at absorbance maxima of $258 \mathrm{~nm}, 262 \mathrm{~nm}$ and $239 \mathrm{~nm}$ for Paracetamol, Chlorpheniramine Maleate and Phenylephrine Hydrochloride in methanol, respectively in bulk mixture and tablet. The Beer Lambert's law obeyed in the concentration range 4-24 $\mu \mathrm{g} / \mathrm{ml}$, for Paracetamol, Chlorpheniramine Maleate and Phenylephrine Hydrochloride respectively. The estimation of bulk mixture and tablet was carried out by simultaneous equation, Q-analysis and area under curve method for estimation of Paracetamol, Chlorpheniramine Maleate and Phenylephrine Hydrochloride. Recovery study was performed to confirm the accuracy of the methods. The methods were validated as per ICH guidelines.

Keywords: Paracetamol, Chlorpheniramine Maleate, Phenylephrine Hydrochloride, Ultraviolet spectroscopy, Simultaneous equation method, Absorption Ratio Analysis Method, Area Under Curve Method.

\section{INTRODUCTION}

Paracetamol (PARA) is chemically $\mathrm{N}$-(4-hydroxyphenyl) acetamide, It has analgesic and antipyretic activity ${ }^{1}$. Various analytical methods, such as, spectrophotometry ${ }^{2,3}$, HPLC ${ }^{4,5}$, HPTLC $^{6}$ have been reported for the estimation of paracetamol from its formulations. Phenylephrine Hydrochloride is [(R)-2-methylamino-1-(3-hydroxyphenyl) ethanol hydrochloride], and used as alpha-adrenergic, sympathomimetic agent as well as vasoconstrictor with little effect on the myocardium or the central nervous system ${ }^{1}$. From literature survey Phenylephrine Hydrochloride has been determined alone or in combination by using UV spectrophotometry ${ }^{2,3}, \quad$ HPLC $^{5}, \quad$ RP-HPLC ${ }^{7}$ methods. Chlorpheniramine maleate (CPM), $( \pm)$ 2-[p-chloro-[2dimethylamino) ethyl] benzyl] pyridine bimaleate (ChlorTrimeton). Chlorpheniramine (Maleate) is the maleate salt of Chlorpheniramine. Chlorpheniramine maleate used as an antihistaminic, it is also effective in nausea, motion sickness ${ }^{1}$. UV spectrophotometry ${ }^{2,3}$, HPLC $^{5}$, RP-HPLC ${ }^{7}$ methods have been reported for the estimation of chlorpheniramine maleate. A mixture of this combination is widely used as an analgesic, antipyretic, decongestant and antihistamine. A combination of paracetamol, phenylephrine hydrochloride, chlorpheniramine maleate is commercially available in tablet dosage form. Literature reveals that no analytical method is available for simultaneous determination of these three drugs in combination. So we communicate here rapid and costeffective quality-control tool for their routine quantitative analysis in pure and combined dosage forms by spectrophotometry.

\section{MATERIAL AND METHOD \\ Materials}

UV-visible double beam spectrophotometer, Jasco model 680 with spectral bandwidth of $1 \mathrm{~nm}$, wavelength accuracy of \pm $0.3 \mathrm{~nm}$ and a pair of $10 \mathrm{~mm}$ matched quartz cells was used. The commercially available tablet, Febrex plus (Label claim: Paracetamol I.P.-500 mg, Chlorpheniramine Maleate $2 \mathrm{mg}$ and Phenylepinephrine hydrochloride) was procured from local market, Methanol, API of Paracetamol, Chlorpheniramine Maleate and Phenylepinephrine Hydrochloride.

\section{Selection of common solvent}

After assessing the solubility of drugs in different solvents Methanol was used as common solvent for developing spectral characteristics.

\section{Preparation of standard stock and calibration curves}

The standard stock solutions $(250 \mu \mathrm{g} / \mathrm{ml})$ of each of Paracetamol, Chlorpheniramine Maleate and Phenylephrine $\mathrm{HCl}$ were prepared separately by dissolving accurately about $25 \mathrm{mg}$ of API in $20 \mathrm{ml}$ of Methanol and volume was made up to $100 \mathrm{ml}$ with methanol. Working standard solutions of 20 $\mu \mathrm{g} / \mathrm{ml}$ were scanned in the entire UV range of $400-200 \mathrm{~nm}$ to obtain the absorbance. Solutions of $20 \mu \mathrm{g} / \mathrm{ml}$ of Paracetamol, Chlorpheniramine Maleate and Phenylephrine $\mathrm{HCl}$ were prepared separately. All these solutions were scanned in the spectrum mode from $200-400 \mathrm{~nm}$. The maximum absorbance of Paracetamol, Chlorpheniramine maleate and Phenylephrine $\mathrm{HCl}$ were at $258 \mathrm{~nm}, 262 \mathrm{~nm}, 239 \mathrm{~nm}$ respectively. Paracetamol, Chlorpheniramine maleate and Phenylephrine $\mathrm{HCl}$ showed linearity in the concentration range of $4-24 \mu \mathrm{g} / \mathrm{ml}$ at their respective maxima. Accurately measured standard stock solution of Paracetamol, Chlorpheniramine Maleate and Phenylephrine $\mathrm{HCl}(1 \mathrm{ml}, 2$ $\mathrm{ml}, 3 \mathrm{ml}, 4 \mathrm{ml}, 5 \mathrm{ml}, 6 \mathrm{ml}$ ) were transferred to a separate series of $10 \mathrm{ml}$ of volumetric flasks and diluted to the mark with Methanol. The absorbance of resulting solutions were measured at their respective max and plotted a calibration curve against concentration to get the linearity and regression equation.

\section{Method 1: Simultaneous Equation Method}

Simultaneous equation method of analysis is based on the absorption of Paracetamol, Phenylephrine Hydrochloride and 
Chlorpheniramine Maleate at the wavelength maximum $(\lambda$ $\max$ ) of each other. $\lambda$-max for Paracetamol, Phenylephrine hydrochloride and Chlorpheniramine maleate are $258 \mathrm{~nm}$, $239 \mathrm{~nm}$ and $262 \mathrm{~nm}$ respectively. The absorptive values determined at $258 \mathrm{~nm}, 239 \mathrm{~nm}$ and $262 \mathrm{~nm}$ for Paracetamol 0.0724 (ax1), 0.0456 (ax2), 0.0220 (ax3), for Phenylephrine hydrochloride 0.0560 (ay1), 0.0430 (ay2), 0.0222 (ay3) and for Chlorpheniramine Maleate 0.0152 (az1), 0.0160 (az2), 0.0424 (az3). These values are means of six estimations. The absorptive coefficients were substituted in equation 1, 2 and 3 to obtain the concentration of drugs ${ }^{2,3,10-12}$.

$$
\begin{aligned}
& \mathrm{A} 1=0.0724 \times \mathrm{Cpa}+0.0560 \times \mathrm{xPh}+0.0152 \times \mathrm{Ccm} \ldots \ldots \ldots(1) \\
& \mathrm{A} 2=0.0456 \times \mathrm{Cpa}+0.0430 \times \mathrm{xPh}+0.0160 \times \mathrm{Ccm} \ldots \ldots \ldots . . . .(2) \\
& \mathrm{A} 3=0.0220 \times \mathrm{CPa}+0.0222 \times \mathrm{cPh}+0.0424 \times \mathrm{Ccm} \ldots \ldots \ldots \ldots(3)
\end{aligned}
$$

Where, CPA, CPH, and CCM are concentrations of Paracetamol, Phenylephrine Hydrochloride and Chlorpheniramine Maleate respectively in $\mu \mathrm{g} / \mathrm{mL}, \mathrm{A} 1, \mathrm{~A} 2$, and $\mathrm{A} 3$ are the absorbance of the sample at $258 \mathrm{~nm}, 239 \mathrm{~nm}$ and $262 \mathrm{~nm}$ respectively.

\section{Method 2: Absorption Ratio Method}

For Q method, $242 \mathrm{~nm}$ (isobestic point) and $258 \mathrm{~nm}(\lambda$-max of PARA) were selected for PARA and PHEN as wavelengths of measurements $250 \mathrm{~nm}$ (isobestic point) and $239 \mathrm{~nm}(\lambda$-max of PHEN) were selected for PHEN and CHLOR as wavelengths of measurements. $234 \mathrm{~nm}$ (isobestic point) and $262 \mathrm{~nm}$ ( $\lambda$-max of CHLOR) were selected for CHLOR and PARA as wavelengths of measurements.

\begin{tabular}{|c|c|c|c|}
\hline \multirow[b]{2}{*}{ CPARA $=$} & (Qm1-QPHEN) & A1 & \\
\hline & (QPARA-QPHEN) & aPARA1 & (4) \\
\hline \multirow[b]{2}{*}{ CPHEN $=$} & (Qm2-QCHLOR) & A1 & \\
\hline & (QPHEN-QCHLOR) & aPHEN1 & ................... (5) \\
\hline
\end{tabular}
Concentrations of PARA, PHEN and CHLOR were determined using following equations $\mathrm{s}^{2,3,10-12}$.

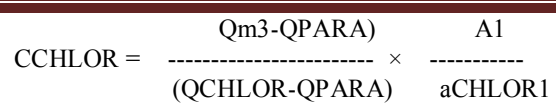

Where; Qm1 = A2 / A1, Qm2=A3 / A2, Qm3=A4 /A3, QPARA = aPARA2/ aPARA1, QPHEN $=$ aPHEN2 / aPHEN1, QCHLOR=aCHLOR2 / aCHLOR1, A2 $=$ Absorbance of Mixture at 258nm, A1 $=$ Absorbance of Mixture at $233 \mathrm{~nm}, \mathrm{~A} 3=$ Absorbance of Mixture at $250 \mathrm{~nm}, \mathrm{~A} 4=$ Absorbance of Mixture at $234 \mathrm{~nm}$

aPARA $1=$ absorptivity of PARA at $233 \mathrm{~nm}$, aPHEN1= absorptivity of PHEN at $233 \mathrm{~nm}$, aPARA2 = absorptivity of PARA at $258 \mathrm{~nm}$, aPHEN2= absorptivity of PHEN at $258 \mathrm{~nm}$, aPHEN1= absorptivity of PHEN at 250 $\mathrm{nm}, \mathrm{aCHLOR} 1=$ absorptivity of CHLOR at $250 \mathrm{~nm}$, aPHEN2= absorptivity of PHEN at $239 \mathrm{~nm}$, aCHLOR2= absorptivity of CHLOR at $239 \mathrm{~nm}$, aCHLOR $1=$ absorptivity of CHLOR at $234 \mathrm{~nm}$, aPARA1 = absorptivity of PHEN at $234 \mathrm{~nm}$, aCHLOR2= absorptivity of CHLOR at $262 \mathrm{~nm}$, aPARA2 = absorptivity of PARA at $262 \mathrm{~nm}$

\section{Method 3: Area under Curve Method Area under curve method for PARA and PHEN in presence of CHLOR}

For the simultaneous determination using the area under curve (AUC) method, suitable dilutions of the standard stock solutions $(250 \mu \mathrm{g} / \mathrm{ml})$ of PARA, PHEN and CHLOR were prepared separately in Methanol. The solutions of drugs were scanned in the range of 200-400 nm. For Area Under Curve method, calibration curve was plotted and the sampling wavelength ranges selected for estimation of PARA, PHEN and CHLOR are $254 \mathrm{~nm}-265 \mathrm{~nm}(\lambda 1-\lambda 2)$ and $232 \mathrm{~nm}-244$ $\mathrm{nm}(\lambda 3-\lambda 4)$ and $257 \mathrm{~nm}-267 \mathrm{~nm}(\lambda 5-\lambda 6)$ respectively and area were integrated between these selected wavelength ranges for three drugs, which showed linear response with increasing concentration hence the same wavelength range were used for estimation of tablet formulations. By using integrated areas three simultaneous equations were constructed and solved to determine concentrations of analytes $^{13,14}$.

\section{(XPHEN at $254-265 \times$ AUCPHEN at $232-244-$ PAPHEN at $232-244 \times$ AUCPARA at $254-265$ ) (XPHEN at 232-244 $\times$ XPARA at 232-244 - XPHEN at 232-244 $\times$ XPARA at 254 - 265) \\ $\mathrm{C}_{\mathrm{PHEN}}=$ \\ (XPARA at 232-244 $\times$ AUCPARA at 254-265 - XPARA at 254-265 $\times$ AUCPHEN at 232 - 244) \\ (XPHEN at 254-265 $\times$ XPARA at $232-244-$ XPHEN at $232-244 \times$ XPARA at $254-265$ ) $(8)$}

Where; $\mathrm{C}_{\mathrm{PARA}}$ and $\mathrm{C}_{\mathrm{PHEN}}-$ Concentration of PARA and PHEN, respectively, $\mathrm{AUC}_{\mathrm{PARA}}$ and $\mathrm{AUC} \mathrm{CHEN}_{\mathrm{PHE}}$ - Area under curve of $\mathrm{AMLB}$ and $\mathrm{HCT}$ in bulk mixture. Similar procedure was applied for determination PARA and PHEN in tablet solution.

Estimation of CHLOR in presence of PARA and PHEN by standard curve method

The absorbance of standard CHLOR solutions at different concentration ranging from $4-24 \mu \mathrm{g} 3 / \mathrm{ml}$ at $262 \mathrm{~nm}$ was measured. The regression equation was established by plotting the calibration curve of absorbance Vs concentration. The absorbance of bulk mixture and tablet solution was measured at $262 \mathrm{~nm}$ for CHLOR. The concentration of CHLOR was estimated by regression equation,

$$
\mathrm{y}=0.021 \mathrm{x}-0.008
$$

Where, y-absorbance of CHLOR in bulk mixture, $\mathrm{x}$ - concentration of CHLOR in tablet solution

\section{Analysis of the tablet formulations}

Twenty tablets of marketed formulation were accurately weighed and powdered. Standard addition method was used for analysis of drugs. A quantity of powder equivalent to 50 $\mathrm{mg}$ of Paracetamol was weighed and dissolved in $100 \mathrm{ml}$ of Methanol. Then the solution was filtered through Whatman filter paper no 41 . From the above $10 \mathrm{ml}$ of solution was diluted to $50 \mathrm{ml}$ with Methanol to get $100 \mu \mathrm{g} / \mathrm{ml}$ of Paracetamol and corresponding Phenylephrine hydrochloride and Chlorpheniramine maleate. From above $2.5 \mathrm{ml}$ of solution was transferred in $10 \mathrm{ml}$ volumetric flask. To this add $0.2 \mathrm{ml}$ of stock solution $(250 \mu \mathrm{g} / \mathrm{ml})$ of pure Phenylephrine Hydrochloride and Chlorpheniramine Maleate and make-up volume up to the mark with Methanol. The purpose of this addition is to bring the concentration of Phenylephrine hydrochloride and Chlorpheniramine Maleate 
in linearity range. With this addition, concentration of Paracetamol, Phenylephrine Hydrochloride and Chlorpheniramine Maleate in the samples was brought to 2.5, 5.5 and $5.1 \mu \mathrm{g} / \mathrm{ml}$ respectively. Analysis procedure was repeated six times with tablet formulation and result reported in Table 1.

\section{Validation}

\section{Linearity}

For each drug, appropriate dilutions of standard stock solutions were assayed as per the developed methods. The Beer- Lambert's concentration range is $4-24 \mu \mathrm{g} / \mathrm{mL}$ for all drugs. The linearity data for all methods are presented in Table $3^{1,15}$.

\section{Accuracy}

Accuracy of the developed method was confirmed by recovery study as per ICH norms at three different concentration levels of $80 \%, 100 \%, 120 \%$ by replicate analysis $(\mathrm{n}=3)$. Here to a pre analyzed sample solution, standard drug solutions were added and then percentage drug content was calculated. The result of accuracy study was reported in Table 2. The recovery study indicates that the method is accurate for quantitative estimation of Paracetamol, Phenylephrine Hydrochloride and Chlorpheniramine Maleate in tablet dosage form as the statistical results are within the acceptance range (S.D. $<2.0$ ).

\section{Precision}

Precision was determined by studying the repeatability and intermediate precision.

\section{Repeatability}

Repeatability result indicates the precision under the same operating conditions over a short interval of time and interassay precision. The standard deviation, coefficient of variance and standard error were calculated. Repeatability was performed for six times with tablets formulation. The results of statistical evaluation are given in Table 1 .

\section{Intermediate Precision (Inter-day and Intra-day precision)}

An intermediate precision was carried out by intra and inter day precision study. In intra-day study concentration of drugs were calculated on the same day at an interval of one hour. In inter day study the drug contents were calculated on three different days. Study expresses within laboratory variation in different days. In both intra and inter-day precision study for the methods \% COV were not more than 1.0 indicates good intermediate precision (Table 3 ).

\section{Limit of Detection (LOD) and Limit of Quantitation (LOQ)}

The LOD and LOQ of Paracetamol, Phenylephrine Hydrochloride and Chlorpheniramine Maleate by proposed methods were determined using calibration standards. LOD and LOQ were calculated as $3.3 / \mathrm{S}$ and $10 / \mathrm{S}$ respectively, where $\mathrm{S}$ is the slope of the calibration curve and is the standard deviation of response. The results of the same are shown in Table 3.

Table 1: Analysis data of tablet Formulation

\begin{tabular}{|c|c|c|c|c|c|c|c|}
\hline Method & Drug & Label claim mg/tab & Amount found mg/tab & Label claim (\%) & S.D. & \% C.O.V. & S.E. \\
\hline \multirow{4}{*}{ I } & PARA & 500 & 500.25 & 100.11 & 0.7608 & 0.7563 & 0.3106 \\
\cline { 2 - 8 } & PHEN & 10 & 9.936 & 99.34 & 0.1625 & 0.1611 & 0.0665 \\
\cline { 2 - 8 } & CHLOR & 2 & 1.9794 & 99.57 & 0.5137 & 0.4987 & 0.2105 \\
\hline \multirow{3}{*}{ II } & PARA & 500 & 495.0 & 99.10 & 0.5674 & 0.7811 & 0.3086 \\
\cline { 2 - 8 } & PHEN & 10 & 10.11 & 100.05 & 1.0077 & 1.2015 & 0.3537 \\
\cline { 2 - 8 } & CHLOR & 2 & 1.88 & 98.02 & 0.5480 & 0.4557 & 0.12227 \\
\hline \multirow{3}{*}{ III } & PARA & 500 & 486.98 & 94.55 & 0.2640 & 0.2640 & 0.1080 \\
\cline { 2 - 8 } & PHEN & 10 & 9.8732 & 97.32 & 1.0775 & 1.0865 & 0.4424 \\
\cline { 2 - 8 } & CHLOR & 2 & 1.87 & 98.01 & 0.9230 & 0.9289 & 0.3562 \\
\hline
\end{tabular}

Table 2: Result of recovery studies

\begin{tabular}{|c|c|c|c|c|}
\hline Method & \multirow{2}{*}{$\begin{array}{c}\text { Recovery level } \\
\text { (added amount) }\end{array}$} & \multicolumn{3}{|c|}{ Drugs } \\
\cline { 2 - 5 } & $80 \%$ & $99.99 \pm 0.1456$ & $99.20 \pm 0.1445$ & $100.20 \pm 0.3538$ \\
\hline \multirow{3}{*}{ I } & $100 \%$ & $98.90 \pm 0.2052$ & $99.70 \pm 0.4567$ & $98.89 \pm 0.1406$ \\
\cline { 2 - 5 } & $120 \%$ & $98.50 \pm 0.6384$ & $98.30 \pm 0.1423$ & $100.30 \pm 0.3578$ \\
\cline { 2 - 5 } & $80 \%$ & $99.40 \pm 0.2395$ & $98.95 \pm 0.5569$ & $99.5 \pm 0.0856$ \\
\hline \multirow{3}{*}{ II } & $100 \%$ & $100.30 \pm 0.6568$ & $99.90 \pm 0.7560$ & $99.32 \pm 0.0856$ \\
\cline { 2 - 5 } & $120 \%$ & $99.80 \pm 0.3401$ & $100.1 \pm 0.3382$ & $99.90 \pm 0.0704$ \\
\cline { 2 - 5 } & $80 \%$ & $99.60 \pm 0.1423$ & $99.47 \pm 0.3985$ & $98.95 \pm 0.9345$ \\
\hline \multirow{2}{*}{ III } & $100 \%$ & $99.75 \pm 0.2376$ & $98.92 \pm 0.6258$ & $99.47 \pm 0.5641$ \\
\cline { 2 - 5 } & $120 \%$ & $98.89 \pm 0.2576$ & $99.87 \pm 0.5832$ & $98.83 \pm 0.3281$ \\
\cline { 2 - 5 } & & \multicolumn{3}{|}{} \\
\hline
\end{tabular}

Table 3: Optical Characteristics data and validation parameters

\begin{tabular}{|c|c|c|c|}
\hline Parameter & \multicolumn{3}{|c|}{ Values } \\
\hline Drugs & PARA & PHEN & CHLOR \\
\hline Working (nm) & 258 & 239 & 262 \\
\hline Beer's law limit $\mu \mathrm{g} / \mathrm{ml}$ & $4-24$ & $4-24$ & $4-24$ \\
\hline Absorptive & 0.0724 & 0.0430 & 0.0424 \\
\hline Correlation coefficient & 0.997 & 0.993 & 0.996 \\
\hline Intercept & -0.053 & 0.062 & -0.008 \\
\hline Slop & 0.098 & 0.052 & 0.021 \\
\hline LOD & 0.4612 & 0.0793 & 0.3512 \\
\hline LOQ & 1.6081 & 0.6858 & 0.5360 \\
\hline Intra-day (precision) (\% C.O.V.) & 0.7131 & 0.3216 & 0.3814 \\
\hline Inter-day (precision) (\% C.O.V.) & 0.9720 & 0.9582 & 0.5706 \\
\hline
\end{tabular}




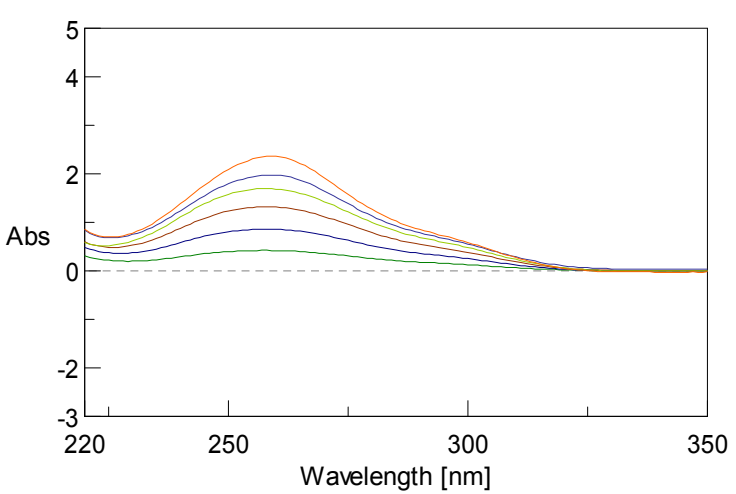

Figure 1: Overlay spectrum of Paracetamol

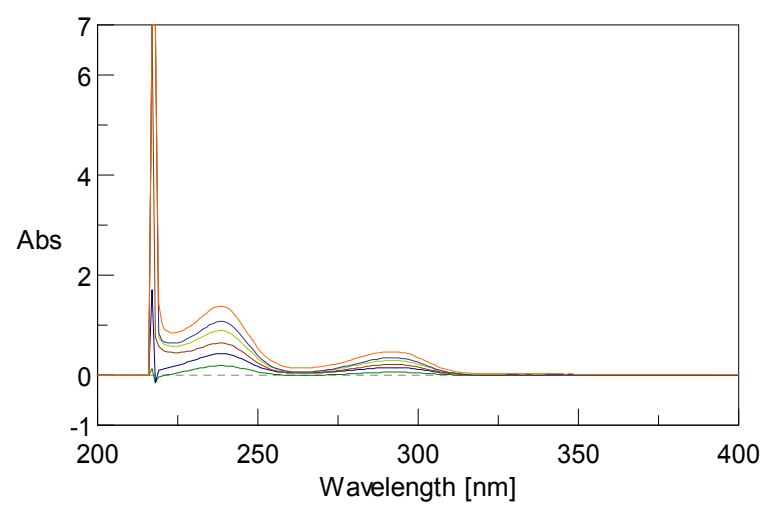

Figure 3: Overlay spectrum of Chlorpheniramine

\section{RESULT}

The proposed methods for simultaneous estimation of PARA, PHEN and CHLOR in combined dosage form were found to be accurate, simple and rapid which can be well understood from vallidation data as given in Table 3 and 4 . The $\%$ R.S.D. Linearity was observed by linear regression equation method for PARA, PHEN and CHLOR in different concentration range. The Correlation coefficient of these drugs was found to be close to 1.00 , indicating good linearity. The assay results obtained by proposed methods as shown in Table 2, hence it can be used for routine analysis of two drugs in combined dosage forms. There was no interference from tablet excipients was observed in these methods. It can be easily and conveniently adopted for routine quality control analysis. These methods are accurate, simple, rapid, precise, reliable, sensitive, reproducible and economic and are validated as per ICH guidelines.

\section{ACKNOWLEDGEMENT}

The authors are thankful to P.D.V.V.P.F's College Of Pharmacy, Vilad Ghat, Ahmednagar, India for providing facilities to carry out this work.

\section{REFERENCES}

1. British pharmacopeia, version 6, volume 1, system simulation Ltd.; 2002.

2. Sawant R, Joshi R, Lanke P and Bhangale L. Simultaneous estimation and validation of Paracetamol, Phenylephrine hydrochloride and Chlorpheniramine maleate in tablets by Spectrophotometric method, JPRHC 2011; 3: 23-28.

3. Sawant Ramesh, Joshi Rupali, Sawant Manisha, Ianke Prashant and Bhangale Lokesh. Mathamatical and multi wavelength Spectrophotometric method for simultaneous estimation of Paracetamol, Phenylphrine hydrochloride Chlorpheniramine maleate and Caffeine, IJPFR; 2011; 1(2): 31-38.

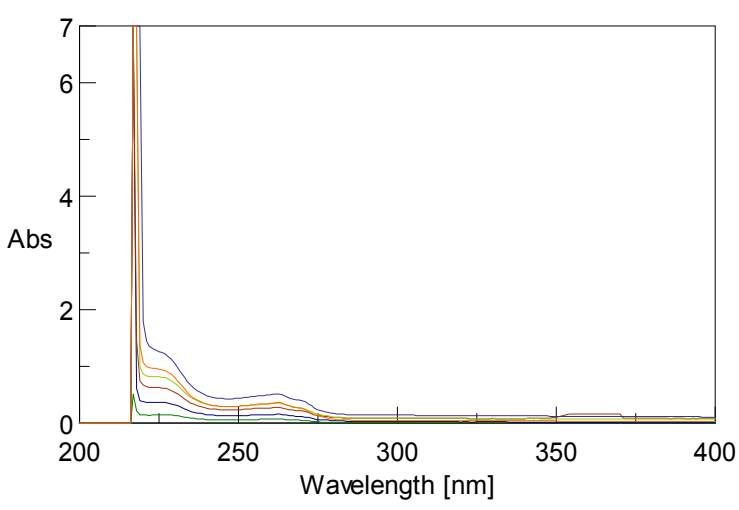

Figure 2: Overlay spectrum of Phenylephrine

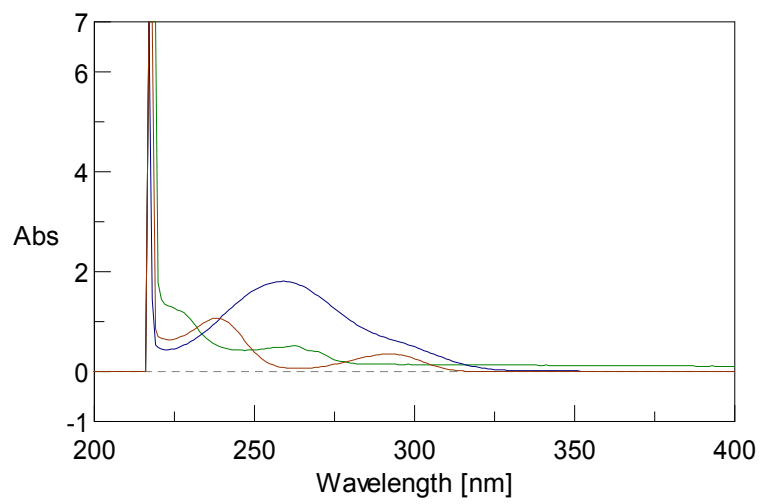

Figure 4: Overlay spectra of PARA, PHEN and CHLOR

4. Zarapkar SS, Hulkar UP, Bhandari NP. Reverse phase HPLC determination of Ibuprofen, Paracetamol and Methocarbamol in tablets. Indian Drugs 1999; 36(11): 710-713.

5. Hamide Çenyuva and Tuncel Ozden. Simultaneous High-Performance Liquid Chromatographic Determination of Paracetamol, Phenylephrine $\mathrm{HCl}$, and Chlorpheniramine Maleate in Pharmaceutical Dosage Forms, Journal of Chromatographic Science 2002; 40: 97-100. http://dx. doi.org/10.1093/chromsci/40.2.97 PMid:11881712

6. Argekar AP, Sawant JG. Simultaneous determination of Paracetamol and Mefenamic acid in tablets by HPTLC. Journal of Planar Chromatography, modern TLC 1999; 12(5): 361-364.

7. Redasani VK, Gorle AP, Badhan RA, Jain PS, Surana SJ. Simultaneous determination of Chlorpheniramine maleate, Phenylephrine hydrochloride, Paracetamol and caffeine in Pharmaceutical preparation by RP-HPLC, Chemical Industry and Chemical Engineering Quarterly 2013; 19(1): 57-65. http://dx.doi.org/10.2298/CICEQ120302042R

8. Tripathi KD. Essentials of Medical Pharmacology, $5^{\text {th }}$ ed. Jaypee Brothers Medical Publishers, New Delhi 2004; 142: 181-182.

9. John M Beale, John H Block. Wilson and Gisvold's textbook of organic medicinal and pharmaceutical chemistry, Lippincott Williams and Wilkins, a Wolters Kluwer business, China $12^{\text {th }}$ ed; 2011. p. 511-512, 532-533, 708 .

10. Beckette AH and Stenlake JB. Practical Pharmaceutical chemistry, $4^{\text {th }}$ ed, part II, CBS Publication and distribution, New Delhi; p. 278-282, 286290.

11. Abdolraouf Samadi Maybodi, Seyed Karim Hassani Nejad Darzi. Simultaneous determination of paracetamol, phenylephrine hydrochloride and chlorpheniramine maleate in pharmaceutical preparations using multivariate calibration, Spertochinica Acta part A: Molecular and bio molecular spectroscopy 2010; 75(4): 1270-1274.

12. Jothieswari D and Ananda Kumar K. Absorption correction method for estimation of amlodipine besylate, valsartan and hydrochlorothiazide in bulk and in combined tablet dosage form. International Journal of Pharmacy and Pharmaceutical Sciences 2011; 3(3): 30-34.

13. Jain NA, Dudane NP, Lohiya RT. Simultaneous determination of metaclopramide and paracetamol by area under curve spectrophotometric method in combined tablet dosage form. Research Journal of Pharmaceutical, Biological and Chemical Sciences 2011; 2(2): $250-255$ 
14. Rana S, Pandya J, Solanki S, Patel M. Development and Validation of Spectrophotometric method for Simultaneous estimation of Lafutidine and Domperidone in combined dosage form by area under curve method, International Journal of Drug Development and Research 2012; 4(1): 257-262.

15. ICH, Q2B, Text on Validation of Analytical Procedure, International Conference On Harmonization, Geneva; 1996. p. 1-8
Cite this article as:

Hapse Sandip Appasaheb, Kapare Parmeshwar Subhash, Dhumal Virashri Atmaram, Damale Pallavi Shankar. Simultaneous estimation and validation of paracetamol, chlorpheniramine maleate and phenylephrine hydrochloride in bulk and tablet dosage form by using different spectrophotometric method. Int. Res. J. Pharm. 2013; 4(10):39-43 http://dx.doi.org/10.7897/ $\underline{2230-8407.041010}$

Source of support: Nil, Conflict of interest: None Declared 